\title{
Peptides and small molecules blocking the CXCR4/CXCL12 axis overcome bone marrow-induced chemoresistance in acute leukemias
}

\author{
SERENA PILLOZZI $^{1}$, ANDREA BERNINI ${ }^{2}$, OTTAVIA SPIGA ${ }^{2}$, BARBARA LELLI ${ }^{3}$, GIULIA PETRONI ${ }^{1}$, \\ LUISA BRACCI $^{3}$, NERI NICCOLAI ${ }^{2}$ and ANNAROSA ARCANGELI ${ }^{1}$ \\ ${ }^{1}$ Department of Experimental and Clinical Medicine, University of Florence, I-50134 Florence; \\ Departments of ${ }^{2}$ Biotechnology, Chemistry and Pharmacy, and ${ }^{3}$ Medical Biotechnology, \\ University of Siena, I-53100 Siena, Italy
}

Received July 20, 2017; Accepted August 16, 2018

DOI: $10.3892 /$ or.2018.6808

\begin{abstract}
Notable advances in treatment have been made and increases in the cure rates of pediatric leukemia have been achieved. However, the majority of children with relapsed disease are not expected to survive, with chemotherapy resistance acting as the principal cause of treatment failure. Interaction between leukemic cells and the bone marrow microenvironment is the primary cause of relapse. It was identified that a multi-protein membrane complex, formed by potassium voltage-gated channel subfamily $\mathrm{H}$ member 2 (hERG1) channels, the $\beta 1$ integrin subunit and the stromal cell-derived factor 12 (CXCL12) receptor, C-X-C chemokine receptor type 4 (CXCR4), exerts a role in mesenchymal stromal cell (MSC)-mediated chemoresistance in pediatric leukemias. hERG1 blockade was able to overcome chemoresistance in vitro and in vivo. As an alternative strategy to overcome chemoresistance, the present study evaluated the effects of novel tools targeting the CXCR4/CXCL12 axis. The analysis of CXCL12 structural dynamics was used for the selection of a peptide (4-1-17) and a small molecule (8673), which interact with a transient hot spot, identified by a dynamic drug design approach. The present findings indicated that peptide 4-1-17 and small molecule 8673 inhibited leukemia cell proliferation and induced a pro-apoptotic effect, which was not reduced by the presence of MSCs. The combined treatment with 4-1-17 and 8673 had a stronger pro-apoptotic effect, particularly on cells cultured on MSCs in normoxic and hypoxic conditions,
\end{abstract}

Correspondence to: Dr Serena Pillozzi, Department of Experimental and Clinical Medicine, University of Florence, 50 Viale G.B. Morgagni, I-50134 Florence, Italy

E-mail: serena.pillozzi@unifi.it

Key words: chemoresistance, leukemia, C-X-C chemokine receptor type 4/stromal cell-derived factor 12 axis, dynamic drug design, protein-protein interaction disruptors, potassium voltage-gated channel subfamily $\mathrm{H}$ member 2 channels, bone marrow stromal cells and was able to overcome MSC-induced resistance to cytarabine. Overall, the targeting of CXCL12 and the ensuing inhibition of the CXCR4/CXCL12 axis may be proposed as an alternative strategy to overcome chemoresistance in leukemia.

\section{Introduction}

Acute leukemia is the most common form of childhood cancer, accounting for $\sim 30 \%$ of pediatric cancer cases $(1,2)$. Despite the considerable progress that has been made in its treatment, this disease remains a leading cause of pediatric cancer-associated mortality, and its prognosis is unfavorable for children with relapsed or refractory disease. The principal cause of treatment failure is chemotherapy resistance $(2,3)$.

An emerging concept suggests that leukemia cells and their interactions with the bone marrow (BM) microenvironment are the primary causes of acute leukemia relapse, due to the survival of residual cells following chemotherapy (4-6). A novel mechanism for the protection exerted by BM mesenchymal stromal cells (MSCs) on acute lymphoblastic leukemia (ALL) cells against chemotherapy has been identified. Pivotal to this mechanism is a multiprotein complex expressed on the plasma membrane of leukemic cells, consisting of potassium voltage-gated channel subfamily $\mathrm{H}$ member 2 (hERG1) channels, the $\beta 1$ subunit of integrin receptors and the stromal cell-derived factor 12 (CXCL12) receptor, C-X-C chemokine receptor type 4 (CXCR4) (hERG1/ $\beta 1 / \mathrm{CXCR} 4)$ (7). These data gave support to the previously demonstrated functional link between hERG1 $\mathrm{K}^{+}$channels and CXCL12 in acute leukemic cell migration (8). Overall, by controlling leukemia cell survival and motility, the hERG1//1/CXCR4 complex has emerged as a target of choice for anti-chemoresistance strategies. Indeed, blocking hERG1 with classical hERG1-specific blockers overcomes MSC-induced chemoresistance, in vitro and in vivo, in ALL mouse models (7).

hERG1 is a voltage-dependent potassium channel, the functional relevance of which in human leukemia has been repeatedly proven (7,9-11). Furthermore, the alternative transcript of the $h E R G l$ gene, $h E R G 1 B$, is an independent 
prognostic factor of a high risk of relapse in pediatric T-ALL (12). Although a number of hERG1-specific blockers exist on the market, a number of them produce adverse cardiac side effects $(13,14)$. Besides developing hERG1B-specific, non-cardiotoxic blockers (15), an alternative strategy to target the hERG1//1/CXCR4 complex in leukemia cells may involve targeting CXCR4 and its ligand CXCL12.

The chemokine receptor CXCR4 is overexpressed in leukemia and is associated with poor outcomes in ALL and acute myeloid leukemia (AML) $(6,16)$. The ligand CXCL12 is constitutively produced by MSCs, particularly under hypoxic conditions (17), and contributes to the migration and survival of leukemic blast cells through the activation of phosphatidylinositol 3-kinase/RAC- $\alpha$ serine/threonine-protein kinase (Akt) and mitogen-activated protein kinase (MAPK) pathways (5). Notably, chemotherapeutic treatments have been demonstrated to upregulate CXCR4 expression. Such upregulation represents a mechanism of acquired resistance in pediatric AML (18). A number of tools have been developed to block CXCR4/CXCL12 interactions, and they are currently under different stages of development (5). Research focused on targeting chemokine receptors has also identified promising molecules, which have subsequently been unsuccessful in clinical trials. Certain of these molecules suffered from low oral bioavailability, e.g. the $\mathrm{C}-\mathrm{C}$ chemokine receptor type 5 (CCR5) inhibitor TAK-779 (19), while others gave rise to severe side effects, e.g. Aplaviroc, also inhibiting CCR5 and causing hepatotoxicity (20). On the other hand, chemokines, commonly considered 'undruggable' due to their small size and shallow surfaces, have re-emerged as drug development targets through novel biochemical approaches (21).

Novel tools targeting CXCL12 have recently been developed by means of combining paramagnetic fragment-based nuclear magnetic resonance (NMR) investigation, molecular dynamics (MD) and docking simulations (22). We here provide in vitro biological data on the effects of some of these molecules on acute leukemia cell survival.

\section{Materials and methods}

Peptides and small molecules. Peptides were synthesized by solid-phase synthesis using standard Fmoc chemistry in a Syro multiple peptide synthesizer (MultiSynTech $\mathrm{GmbH}$, Witten, Germany). The final product was cleaved from the solid support, deprotected by treatment with trifluoroacetic acid containing tri-isopropylsilane and water (95/2.5/2.5), and precipitated with diethyl ether. Crude peptides were purified by reverse-phase chromatography. The final peptide purity and identity were confirmed by reverse-phase chromatography on a Phenomenex Jupiter C18 analytical column and by mass spectrometry with a Bruker Daltonics ultraflex matrix assisted laser desorption/ionization-time of flight tandem system (Bruker Corporation, Billerica, MA, USA). Peptide 4-175-185 MS: Calculated for C79H129N21O28S was 1,853.05; detected $1,854.19 \mathrm{~m} / \mathrm{z}$; high-performance liquid chromatography (HPLC) room temperature (RT) [80\% eluent A (DDW)-5\% eluent A (DDW)], 18.37 min. Peptide 4-29-35 MS: Calculated for $\mathrm{C} 63 \mathrm{H} 102 \mathrm{~N} 18 \mathrm{O} 21 \mathrm{~S}$ was $1,479.65$; detected $1,480.96 \mathrm{~m} / \mathrm{z}$; HPLC RT (80\%A-5\%A) 14.92 min. Peptide 4-1-17 MS: Calculated for C108H170N24O40S3 was 2,540.83; detected
250.96; HPLC RT (80\%A-1\%A) 21.64 min. Peptide 7-1-17 MS: Calculated for C117H174N26O37S2 was 2,600.91; detected $2,598.29 \mathrm{~m} / \mathrm{z}$. HPLC RT (from $80 \% \mathrm{~A}-20 \% \mathrm{~A}$ ) $23.33 \mathrm{~min}$. Positive ion mode was used in all cases. All surface plasmon resonance experiments were performed on a BIA T100 system (GE Healthcare, Chicago, IL, USA). The binding of CXCL12 was performed on a streptavidin (SA)-sensor chip previously coated with biotinylated peptides. The immobilization of the biotinylated peptide(s) was achieved by injecting peptide(s) diluted at $50 \mu \mathrm{g} / \mathrm{ml}$ in $\mathrm{HBS}-\mathrm{EP}^{+}(10 \mathrm{mM}$ HEPES, $150 \mathrm{mM}$ $\mathrm{NaCl}, 3.4 \mathrm{~m}$ EDTA, $0.05 \%$ polysorbate 20; pH 7.4) for $60 \mathrm{sec}$ over an SA-coated flow cell at the flow rate of $10 \mu \mathrm{l} / \mathrm{min}$. The binding of CXCL12 with immobilized peptides was investigated using injections for $180 \mathrm{sec}$ at chemokine concen-

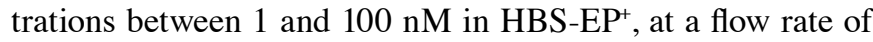
$30 \mu \mathrm{l} / \mathrm{min}$. The regeneration of the matrix was achieved by flushing a short pulse of $1 \mathrm{M} \mathrm{NaCl}-10 \mathrm{mM} \mathrm{NaOH}$. For small molecule binding, CXCL12 was immobilized on a dextran matrix of a CM4 sensor chip flow cell via a standard amino coupling procedure. A flow cell was used as a reference surface following a blank immobilization. Small molecules were injected over a CXCL12-coated chip for $60 \mathrm{sec}$ at a flow rate of $30 \mu \mathrm{l} / \mathrm{min}$ and diluted at $100 \mu \mathrm{M}$ in $5 \%$ dimethyl sulfoxide-HBS-EP ${ }^{+}$, which was also used as the running buffer. Molecular docking simulation was performed using the AutoDock Vina package v 1.1.2 (23) using a ZINC-derived library (http://zinc.docking.org) of small molecules probed against a CXCL12 pocket region previously identified by NMR experiments and MD simulations (22), and consisting of residues V23, K24, H25, K27, A40, R41 and K43. Standard Vina parameters were used for the simulation runs. Selected molecules were purchased from ChemBridge Corporation (San Diego, CA, USA).

Cell culture. Leukemia cell lines [B-cell precursor-ALL (BCP-ALL) 697 cells and AML FLG 29.1 cells] and normal Epstein-Barr virus (EBV)-infected B lymphocytes were cultured in RPMI-1640 medium (Sigma-Aldrich; Merck KGaA, Darmstadt, Germany) supplemented with $2 \mathrm{mM}$ L-glutamine (EuroClone SpA, Pero, Italy) and 10\% fetal calf serum (FCS; EuroClone). Human BM-derived MSCs immortalized by enforcing the expression of telomerase reverse transcriptase in primary MSCs were established in the laboratory of Dr D. Campana (Department of Pediatrics, National University of Singapore, Singapore) and maintained as described previously (7).

MSCs were seeded in 96-well flat-bottomed plates coated with fibronectin $(1 \mu \mathrm{g} /$ well) and grown until confluence prior to undertaking the co-culture experiments.

Primary samples. BM samples from children with newly diagnosed AML were analyzed at the Hematology-Oncology Laboratory of the Department of Pediatrics, University of Padua (Padua, Italy). Diagnoses were made according to standard cytomorphology, cytochemistry, an immunophenotypic criteria as described previously (12). Patients studied were enrolled in the AIEOP-BFM ALL 2009 therapy protocol, approved by the local ethical committee (Comitato Etico per la Sperimentazione dell'Azienda Ospedaliera di Padova; no. 0002862-18/01/2012). The parents or legal guardians of 
the patients provided written informed consent, following the tenets of the Declaration of Helsinki.

Trypan blue assay. Cell viability was assessed by trypan blue exclusion assay. In brief, $20 \mu 10.4 \%$ trypan blue solution was added to $20-\mu 1$ cell suspensions in culture medium. The suspension was gently mixed and transferred to a hemocytometer. Viable and dead cells were identified and counted under a light microscope (x10 magnification) Blue cells failing to exclude the dye were considered nonviable, and transparent cells were considered viable. The percentage of viable cells was calculated on the basis of the total number of cells (viable and non-viable). The median lethal dose $\left(\mathrm{LD}_{50}\right)$ value was calculated by fitting the data points (following $24 \mathrm{~h}$ of incubation) with a sigmoidal curve using OriginPro 2015 (OriginLab, Northampton, MA, USA).

Pharmacology experiments. Leukemic cells were serumstarved for $16 \mathrm{~h}$ in RPMI medium and seeded in 96-well flat-bottomed plates (Corning-Costar; Corning Incorporated, Corning, NY, USA) at a cell density of $2 \times 10^{5}$ cells/well in RPMI containing $10 \%$ FCS.

Small molecules and peptides were used at the $\mathrm{LD}_{50}$ values indicated in the figures following three different schedules: i) Single treatment (added at timepoint 0); ii) double treatment (added at timepoints 0 and $12 \mathrm{~h}$ ); and iii) triple treatment (added at timepoints 0,12 and 24 h).

Following 24, 48 and $72 \mathrm{~h}$ of incubation, viable cells (determined by the trypan blue exclusion test) were counted in triplicate using a hemocytometer. Each experimental point represents the mean of four samples from three independent experiments.

Co-culture experiments. Cell suspensions (at a cell density of $2 \times 10^{5}$ cells/well) were placed in a 96-well flat-bottomed plate, with or without bone marrow-derived MSCs and treated with 4-1-17 or 8673 at the $\mathrm{LD}_{50}$ dose alone, or in combination with cytarabine $(45 \mathrm{nM})$ or doxorubicin $(0.1 \mu \mathrm{g} / \mathrm{ml})$. Cultures were maintained for $48 \mathrm{~h}$ at $37^{\circ} \mathrm{C}, 5 \% \mathrm{CO}_{2}$ and $90 \%$ humidity. Following incubation, cells were separated from MSCs by pipetting with ice-cold PBS, and were processed for apoptosis or caspase activity analyses.

Apoptosis analysis. The Annexin V/propidium iodide (PI) (Annexin V-FLUOS staining kit; Roche Diagnostics, Basel, Switzerland) test was applied to measure apoptosis. Leukemia cells were washed twice with PBS, resuspended in $100 \mu 1$ assay buffer, and incubated with fluorescein isothiocyanate-conjugated Annexin V and PI. The mixture was incubated at room temperature for $15 \mathrm{~min}$ prior to flow cytometric analysis. Data were analyzed using BD FACSDiva Software 6.1.3 (BD Biosciences, Franklin Lakes, NJ, USA) as described in (7).

Caspase activity assay. The generic caspase activity assay kit (Fluorometric-Green; cat. no. ab112130; Abcam, Cambridge, UK) was used to detect the activity of caspases 1, 3, 4, 5, 6, 7, 8 and 9. Leukemic cells were treated for $48 \mathrm{~h}$ (as discussed above) and subsequently incubated at $37^{\circ} \mathrm{C}, 5 \% \mathrm{CO}_{2}$ for $2 \mathrm{~h}$ with $2 \mu 1$ 500X TF2-VAD-FMK. Following PBS washing, cells were resuspended in $0.5 \mathrm{ml}$ assay buffer and analyzed with BD FACSDiva Software 6.1.3 (BD Biosciences).

Hypoxia experiments. Exponentially growing cells were treated as described above and incubated at $37^{\circ} \mathrm{C}$ in $0.1 \%$ $\mathrm{O}_{2}$ (water-saturated atmosphere containing $94.9 \% \mathrm{~N}_{2}$ and $5 \% \mathrm{CO}_{2}$ ) in a DG250 Anaerobic Workstation (Don Whitley Scientific, Ltd., Bingley, UK) for $48 \mathrm{~h}$.

Western blotting. Protein extraction and western blotting were performed largely as described in (7). Leukemic cells following treatment were washed with cold PBS and immediately extracted with $1 \%$ NP-40 lysis buffer (1\% NP-40, $150 \mathrm{mM} \mathrm{NaCl}, 50 \mathrm{mM}$ Tris- $\mathrm{HCl}, \mathrm{pH} 8,5 \mathrm{mM}$ EDTA and $10 \mathrm{mM} \mathrm{Na}_{4} \mathrm{P}_{2} \mathrm{O}_{7}$ ) supplemented with a tablet of a complete mix of protease inhibitors (Roche Complete Mini; Roche Diagnostics). Cell lysates were centrifuged at 13,000 x g for $10 \mathrm{~min}\left(4^{\circ} \mathrm{C}\right)$, and the supernatants were collected and assayed for protein concentration with the Bradford protein assay method (Bio-Rad Laboratories, Inc., Hercules, CA, USA). Proteins were eluted by boiling the samples in Laemmli buffer, analyzed by SDS-PAGE (7.5\%) under reducing conditions, and transferred to a nitrocellulose membrane (Hybond P; Amersham; GE Healthcare). The membrane was incubated for $4 \mathrm{~h}$ at room temperature with $0.1 \%$ Tween-20 in PBS (T-PBS) containing 5\% bovine serum albumin, Sigma-Aldrich; Merck KGaA) and incubated overnight at $4^{\circ} \mathrm{C}$ with the appropriate primary antibodies at the concentrations listed below. Membranes were washed three times with T-PBS and incubated with the appropriate secondary antibodies for $45 \mathrm{~min}$ at room temperature. Following three washes with T-PBS, the immunoreactivity was determined by an enhanced chemiluminescence reaction (SuperSignal; Pierce; Thermo Fisher Scientific, Inc., Waltham, MA, USA). For the stripping of the membranes, the ReBlot WB recycling kit (Chemicon; EMD Millipore, Billerica, MA, USA) was used, according to manufacturer's protocol.

The following primary antibodies were used: Antiphospho-p44/42 MAPK (Thr202/Tyr204) (Cell Signaling Technology, Inc., Danvers, MA, USA; cat. no. 9101; dilution, 1:500) and anti-pAkt1/2/3 (Thr308)R (Santa Cruz Biotechnology, Inc., Dallas, TX, USA; cat. no. sc-271966; dilution, 1:500). Anti- $\alpha$-tubulin mouse monoclonal (Sigma-Aldrich; Merck KGaA; cat. no. T9026; dilution, 1:500), anti-tAkt1/2/3 (H-136) (Santa Cruz Biotechnology, Inc.; cat. no. sc8312; dilution, 1:500), anti-extracellular signal-regulated kinase (ERK)1 (C-16) (Santa Cruz Biotechnology, Inc.; cat. no. sc-292838; dilution, 1:500) antibodies were used as loading controls. Secondary antibodies for western blotting included anti-rabbit peroxidase-conjugate (Sigma-Aldrich; Merck KGaA; cat. no. A0545; dilution, 1:10,000) and anti-mouse peroxidase conjugate (Sigma-Aldrich; Merck KGaA; cat. no. A4416; dilution, 1:5,000).

Western blotting images were acquired with an Epson 3200 scanner, and the relative bands analyzed with Scion Image software version 4.0 (Scion Corporation, Frederick, MD, USA). The intensity of the bands was normalized to the intensity of the bands that corresponded to the total protein. The control cell ratio was set as 1 . 
Statistical analysis. Graphs and statistical analyses were prepared using Prism 4.00 (GraphPad Software, Inc., La Jolla, CA, USA). Values in all panels are the mean \pm standard deviation of three independent experiments. The normality of the data distribution was checked with the Kolmogorov-Smirnov test. In the case of normal distributions, each dataset was first checked for variance homogeneity, using the Brown-Forsythe test for multiple comparisons. For multiple comparisons, one-way analysis of variance followed by Bonferroni's post hoc test was performed to derive the $\mathrm{P}$-values. $\mathrm{P}<0.05$ was considered to indicate a statistically significant difference.

\section{Results}

Selection of peptides from CXCR4. Amino acid (aa) residues involved in, and putatively modulating, the CXCR4/CXCL12 interaction were identified from CXCR4 fragments located in regions in which the interaction with CXCL12 had been inferred either by mutagenesis (24), structural modeling of the ligand receptor/complex (25), NMR evaluation of the binding of CXCR4 N-terminal peptides spanning aa 1-27 (26), or the NMR-derived structure of CXCL12 in complex with a CXCR4 N-terminal fragment spanning aa 1-38 (27). Comparison of the two NMR studies allowed for the accurate selection of a shorter (thus more suitable as a molecular tool) peptide, strongly interacting with CXCL12 and spanning aa 1-17 of CXCR4 (termed peptide 4-1-17). Such a fragment exhibits a large interaction surface in the complex CXCL12/CXCR4 ${ }_{1-38}$ (27) (Fig. 1; left) and marked binding (in terms of NMR chemical shift perturbation) when used as a fragment against CXCL12 (26). The left panel of Fig. 1 illustrates the mode of interaction of peptide 1-17 with the chemokine as derived from the complex CXCL12/CXCR4 ${ }_{1-38}$ (Protein Data Bank ID 2K04; http://www. rcsb.org); a strong interaction between the peptide and the crevice surface formed by the $\mathrm{N}$-terminal and the central $\beta$-sheet of CXCL12 is apparent.

The $\mathrm{CXCR}_{18-27}$ sequence, on the contrary, exhibited no binding to CXCL12 when used as a fragment. Due to the lack of binding data for the remaining sequence $\mathrm{CXCR} 4_{28-38}$ and the large conformational variability in the CXCL12/CXCR4 $4_{1-38}$ structure, the peptide spanning aa 29-35 (termed 4-29-35) of CXCR4 was selected for the evaluation of binding capability of this region. Although no other experimental structural data are available for CXCR4, mutagenesis and modeling studies $(24,25)$ indicated the second extracellular loop ECD2 as being involved in ligand binding and signaling, due to its interaction with the CXCL12 loop linking $\beta$-strands I and II. Thus, the $\mathrm{CXR}_{175-185}$ fragment spanning the ECD2 sequence was selected for evaluation (termed 4-175-185). CXCL12 binding to another seven-transmembrane span receptor, CXCR7 (28), suggested the selection of an additional peptide from the latter one. Although the structure of CXCR7 remains to be resolved, comparative molecular modelling predicted that interacting regions of CXCR4 and CXCR7 with CXCL12 are similarly located in the N-terminal region (29). Hence, to exploit the CXCR4/CXCR7/CXCL12 chemokine axis, the sequence segment spanning the $\mathrm{N}$-terminal residues 1 to 17 of the CXCR7 was selected to obtain a peptide (termed 7-1-17) homologous to 4-1-17.
Selection of small molecules. Small molecules modulating the CXCR4/CXCL12 interaction were selected from a virtual library [Clean Leads subset from ZINC database; (30)] using experimental data as constraints for a molecular docking simulation. In particular, all molecules were docked to the transient binding pocket opening on Val23/Ala40 (22). Transient pockets, indeed, refer to their rapid appearance and disappearance on flat protein surfaces as a consequence of fluctuations in conformational dynamics [hence the definition of dynamic drug design (DDD)]. The presence of such a pocket was inferred by an NMR paramagnetic perturbation study, while the open conformation was determined by trajectory analysis of molecular dynamics simulation of CXCL12 (22). The trajectory frame representing the pocket open conformation was used for the docking run, and the simulation box was narrowed down to the involved residues V23, K24, H25, K27, A40, R41 and K43. A total of one out of the three chosen small molecules, henceforth termed 8673 , had already been reported to interact with CXCL12 in previous investigations (31), and its binding geometry is reported in Fig. 1 (right panel).

Selected peptides and small molecules were tested for chemokine binding by surface plasmonic resonance (see Tables I and II).

Effect of peptides and small molecules targeting CXCL12 on leukemia cell vitality and proliferation. The panel of molecules reported above was tested in a viability assay. For each molecule, the $\mathrm{LD}_{50}$ in AML (FLG 29.1) and ALL cell lines (697) were determined. Dose-dependence curves and $\mathrm{LD}_{50}$ values measured following $24 \mathrm{~h}$ of treatment are presented in Fig. 2 and Table I, respectively. Peptide 4-1-17 and the small molecule 8673 had a strong anti-proliferative effect on the two leukemic cell lines at micromolar concentrations. Similar effects were observed for small molecule 9430, although to a lesser extent. On the other hand, 4-175-185 and 9355, which did not bind CXCL12 in the SPR assay (see Table II), did not exert any effects on cell viability at concentrations up to $100 \mu \mathrm{M}$.

Fig. 3 illustrates the effects of 4-1-17 (Fig. 3A) and 8673 (Fig. 3B), tested at their $\mathrm{LD}_{50}$ value, on the proliferation of FLG 29.1 and 697 leukemic cells, in addition to that of normal EBV-infected B lymphocytes. The two molecules almost completely inhibited cell proliferation in either leukemic cell lines in the first $24 \mathrm{~h}$ of incubation. Subsequently, cells recommenced proliferation, although at a lower rate. However, when the two compounds were re-added to the cells following 12 and $24 \mathrm{~h}$ of incubation, leukemia cell proliferation was almost abolished. On the contrary, 4-1-17 and 8673 did not affect the cell viability of normal EBV-infected B lymphocytes (Fig. 3A and B lower panels).

Effect of peptides and small molecules targeting CXCL12 on leukemia cell apoptosis. The effects of 4-1-17 and 8673 on cellular apoptosis were also tested (at their $\mathrm{LD}_{50}$ value) on the two leukemia cell lines (FLG 29.1 and 697) and on primary BCP-ALL samples, in suspension or co-culture with MSCs (as in 7) and in the absence or presence of classical chemotherapeutic drugs (cytarabine in AML, or doxorubicin in ALL). As expected $(7,32,33)$, MSCs significantly protected leukemic cells from either spontaneous, or cytarabine-(in AML) or doxorubicin-(in ALL) induced apoptosis (Fig. 4). On the contrary, 

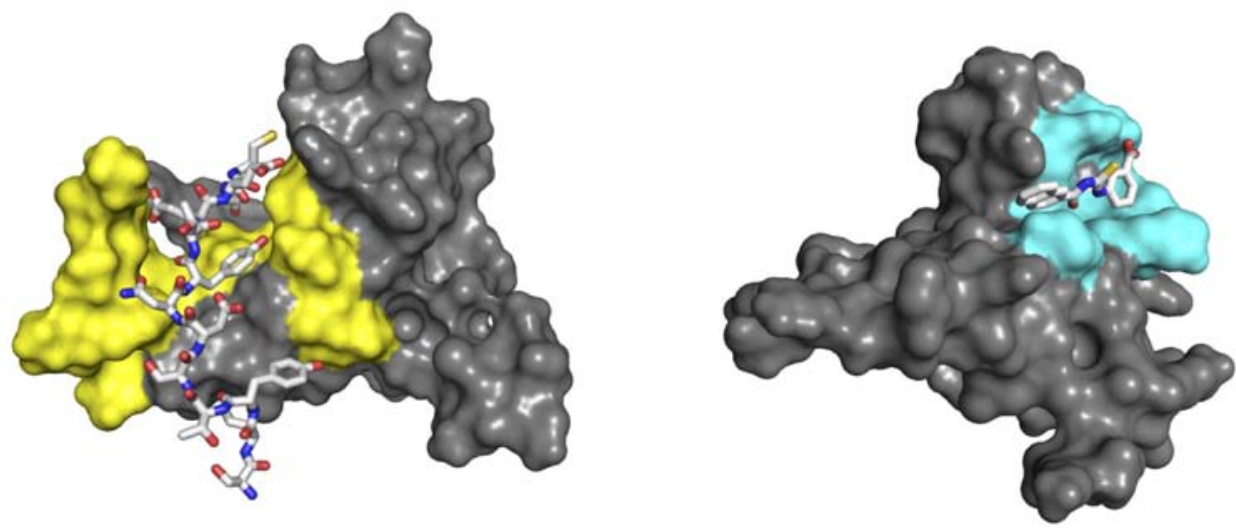

Figure 1. Molecular models of CXCL12 bound to 4-1-17 and 8673. Molecular models of CXCL12 (represented as grey surfaces) bound to 4-1-17 (sticks, left) and 8673 (sticks, right), as derived from the nuclear magnetic resonance structure and molecular docking simulations, respectively. The interacting surfaces were formed by the N-terminal segment and the central beta-sheet (yellow, left), and an open-state transient pocket involving residues V23, K24, H25, K27, A40, R41 and K43 (cyan, right). CXCL12, stromal cell-derived factor 12.
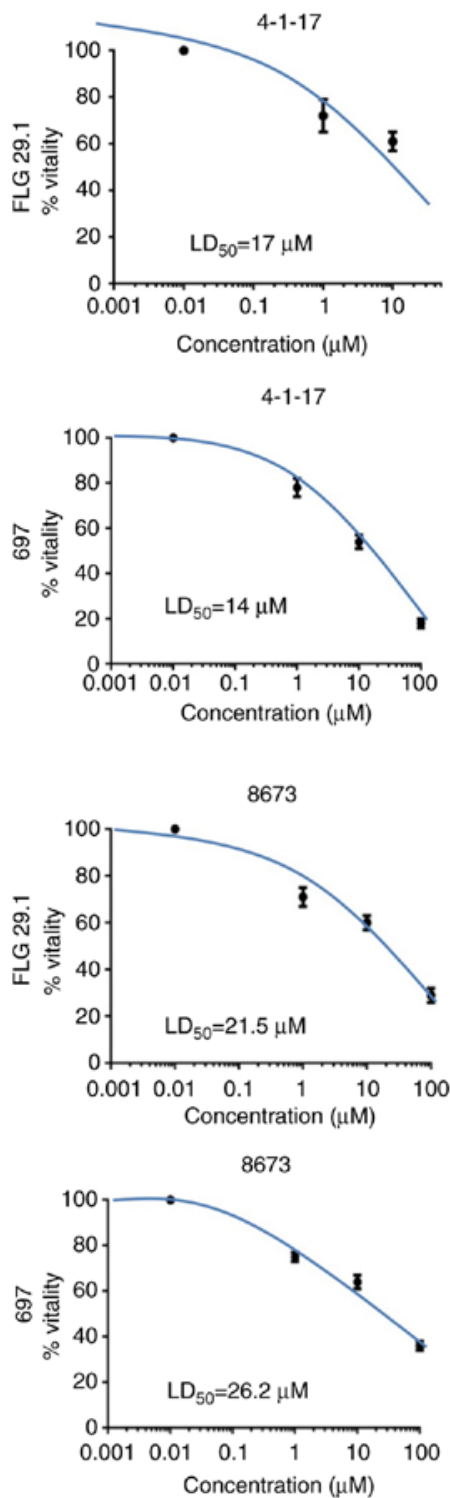
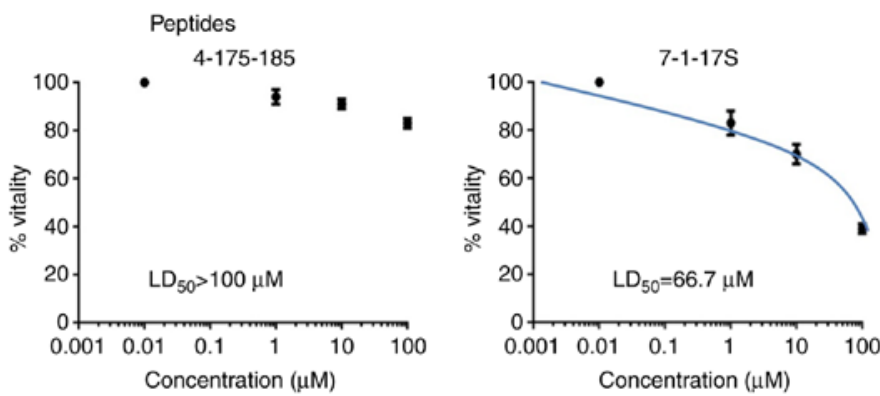

4-175-185
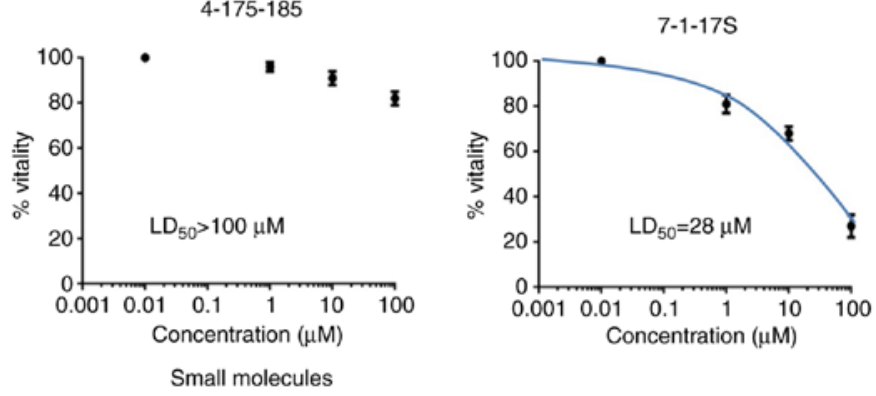

9430
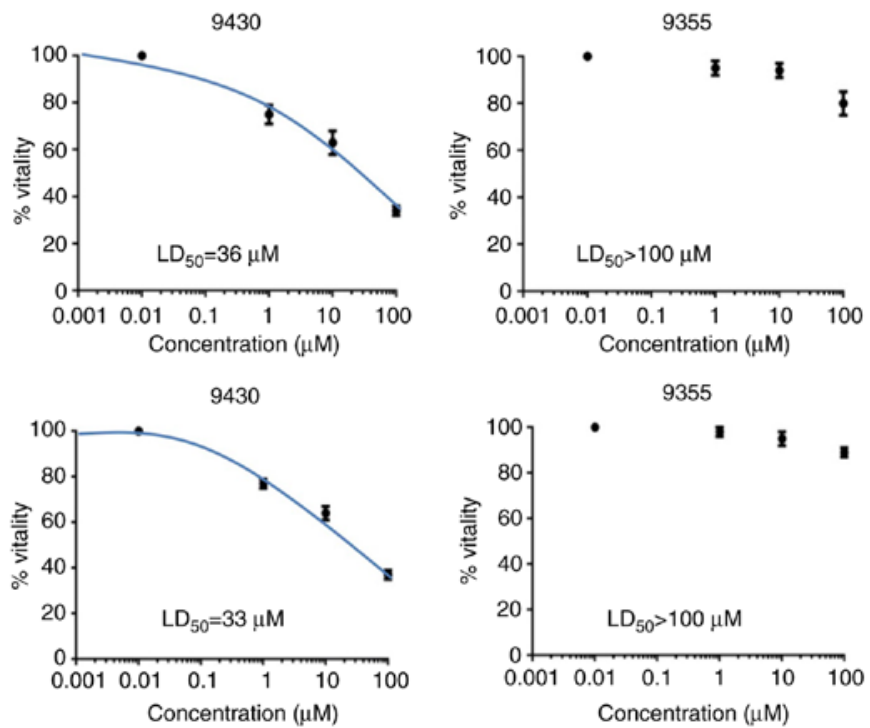

Figure 2. Dose response curves for peptides and small molecules targeting CXCL12 in leukemic cell lines. Acute myeloid leukemia (FLG 29.1) and B-cell precursor-acute lymphoblastic leukemia (697) cells were cultured and exposed to increasing concentrations of peptides and small molecules for 24 h. The percentage of trypan blue-negative cells was measured. $\mathrm{LD}_{50}$ values were evaluated by nonlinear regression analysis using OriginPro 2015 . Values in all panels are the mean \pm standard deviation of three independent experiments. Statistical analysis was performed with one-way analysis of variance followed by Bonferroni's post hoc test. $\mathrm{LD}_{50}$, median lethal dose. 
Table I. Peptides.

\begin{tabular}{|c|c|c|c|c|c|c|c|}
\hline \multirow[b]{2}{*}{ Code } & \multirow{2}{*}{$\begin{array}{c}\text { CXCR4 } \\
\text { sequence span }\end{array}$} & \multirow{2}{*}{$\begin{array}{c}\text { CXCR7 } \\
\text { sequence span }\end{array}$} & \multirow[b]{2}{*}{ Sequence } & \multirow[b]{2}{*}{ MM } & \multirow[b]{2}{*}{$\mathrm{K}_{\mathrm{d}}, 298 \mathrm{~K}$} & \multicolumn{2}{|c|}{$\mathrm{LD}_{50}, \mu \mathrm{M}$} \\
\hline & & & & & & FLG 29.1 & 697 \\
\hline $4-1-17$ & $1-17$ & - & MEGISIYTSDNYTEEMG & 1,940 & $7.51 \times 10^{-7}$ & $17.0 \pm 1.2$ & $14 \pm 1.1$ \\
\hline $4-175-185$ & $175-185$ & - & ANVSEADDRYI & 1,253 & No binding & $>100$ & $>100$ \\
\hline $4-29-35$ & $29-35$ & - & FREENAN & 879 & No binding & $\mathrm{Nd}$ & $\mathrm{Nd}$ \\
\hline $7-1-17$ & - & $1-17$ & MDLHLFDYSEPGNFSDI & 2,000 & $4.57 \times 10^{-8}$ & $66.7 \pm 2.3$ & $28 \pm 1.4$ \\
\hline
\end{tabular}

CXCR4, C-X-C chemokine receptor type 4; CXCR7, atypical chemokine receptor 3; $\mathrm{K}_{\mathrm{d}}$, dissociation constant; $\mathrm{LD}_{50}$, median lethal dose; $\mathrm{MM}$, molecular mass. Nd, not determined.

A

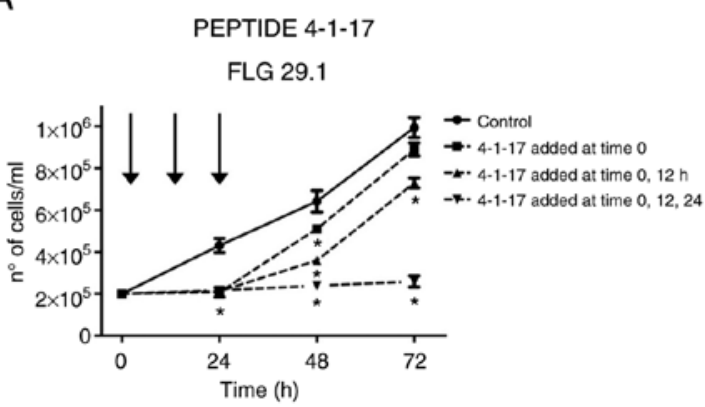

697

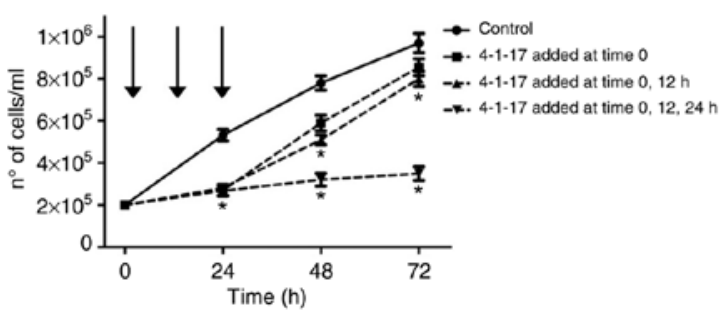

EBV-infection B lymphocytes

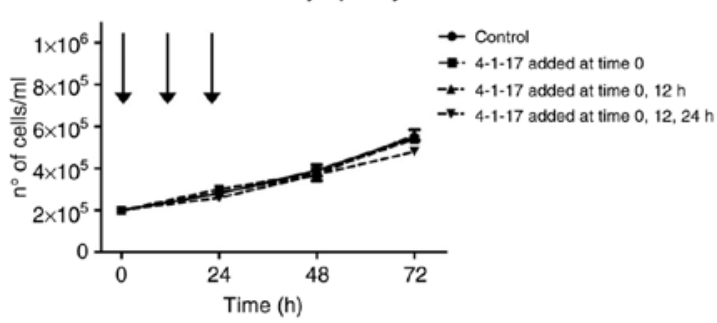

B

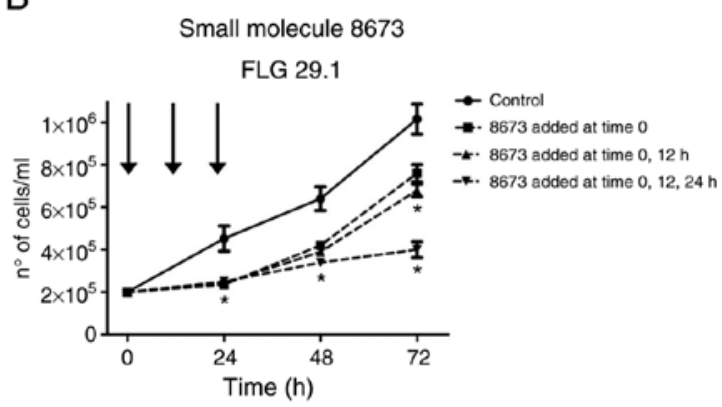

697

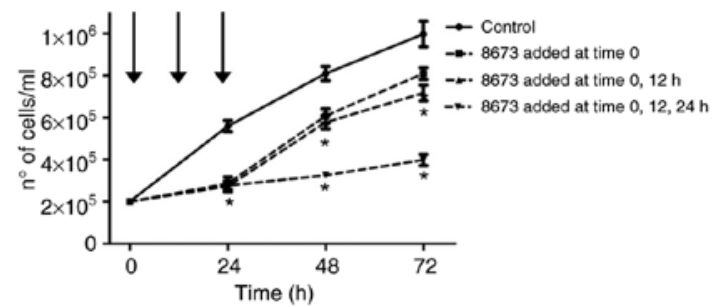

EBV-infection B lymphocytes

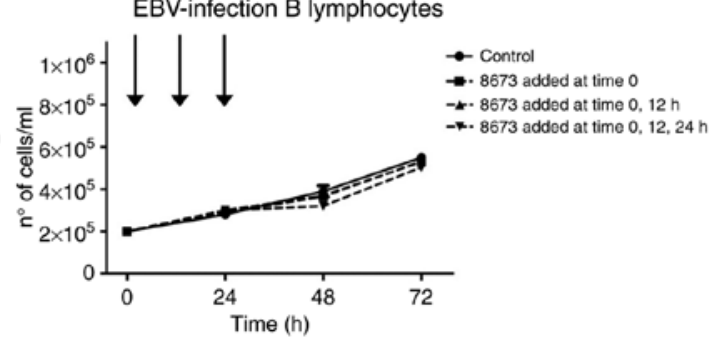

Figure 3. Peptide 4-1-17 and small molecule 8673 inhibit leukemia cell proliferation. (A) Effects of peptide 4-1-17 on FLG 29.1 and 697 leukemic cells and EBV-infected B lymphocytes; proliferation following a single (at timepoint 0 ), a double (at timepoints 0 and 12 h) and a triple treatment (at timepoints 0,12 and $24 \mathrm{~h}$ ) is given as the number of trypan blue-negative cells. (B) Effects of small molecule 8673 on leukemic FLG 29.1 and 697 cells and EBV-infected B lymphocytes; proliferation following a single (at timepoint 0 ), a double (at timepoints 0 and $12 \mathrm{~h}$ ) and a triple treatment (at timepoints 0 , 12 and $24 \mathrm{~h}$ ) is given as the number of trypan blue-negative cells. Timings of treatments are indicated by the arrows. Values in all panels are the mean \pm standard deviation of four independent experiments. Statistical analysis was performed with one-way analysis of variance followed by Bonferroni's post hoc test. "P<0.05 vs. control. EBV, Epstein-Barr virus.

the pro-apoptotic effects exerted by either 4-1-17 or 8673 were not reduced by MSCs in AML and ALL cells (Fig. 4).

Since 4-1-17 and 8673 bind CXCL12 at different sites, the effects of the combination of the two molecules were tested in FLG 29.1 cells cultured either in suspension or onto MSCs. The combined treatment had a strong pro-apoptotic effect, evidenced by the increase in the percentage of apoptotic cells and by caspase activation (Fig. 5A and B). This effect was more evident in cells cultured on MSCs, and even more when cells were treated with cytarabine. Overall, these data indicated that peptide 4-1-17 and small molecule 8673 overcame MSC-induced resistance to cytarabine (Fig. 5). 
Table II. Small molecules.

$$
\mathrm{LD}_{50}, \mu \mathrm{M}
$$

\begin{tabular}{llllll} 
Code Zinc ID & Formula & $\mathrm{MM}$ & $\mathrm{K}_{\mathrm{d}}, 298 \mathrm{~K}$ & FLG 29.1 \\
\hline 8673 & 00310454 & 349.4 & $0.5 \times 10^{-6}$ & $21.5 \pm 1.2$ \\
9355 & 19558063 & 346.4 & No binding & $>100$ & \\
9430 & 20418702 & 309.3 & No binding & $36.2 \pm 1.8$ \\
\hline
\end{tabular}

$\mathrm{K}_{\mathrm{d}}$, dissociation constant; $\mathrm{LD}_{50}$, median lethal dose; $\mathrm{MM}$, molecular mass.

A

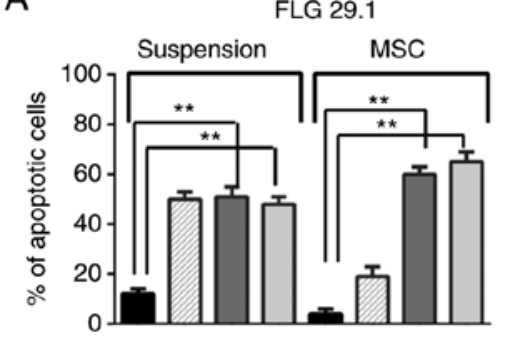

C

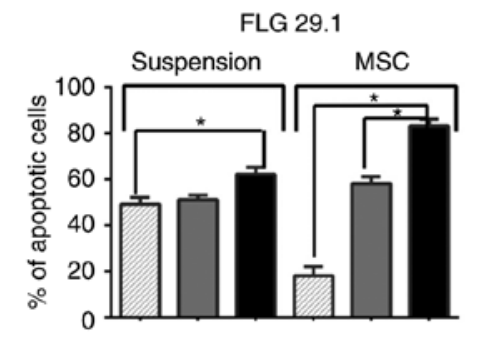

E

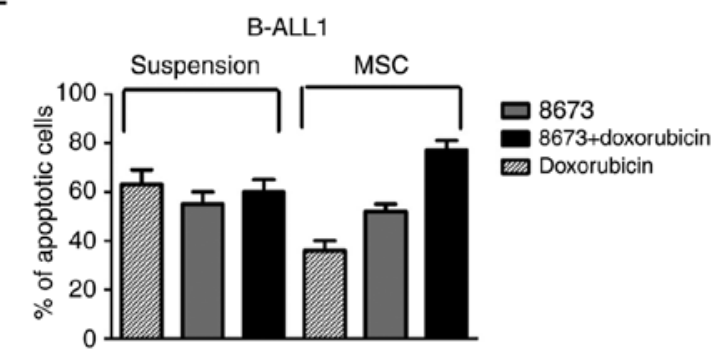

B

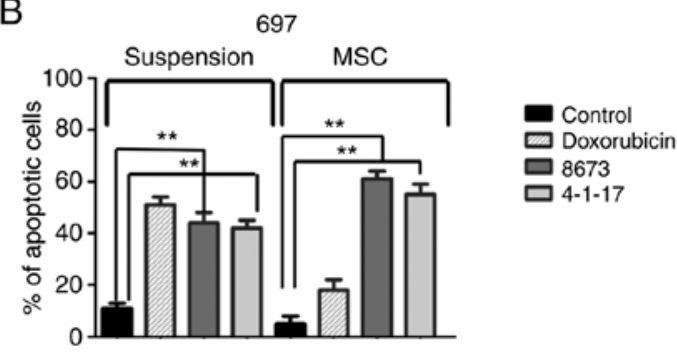

D

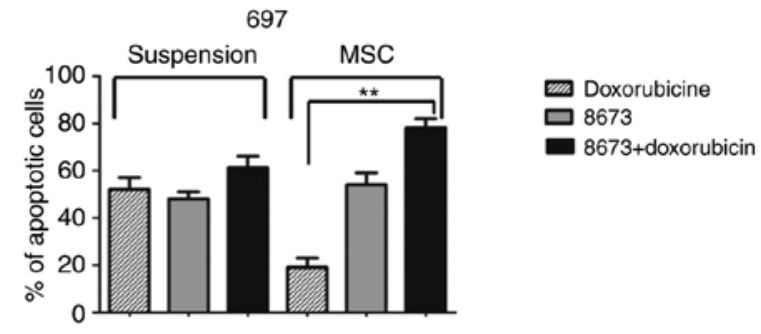

Figure 4. Pro-apoptotic effect of peptide 4-1-17 and small molecule 8673 in AML and ALL cell lines. (A) The AML cell line FLG 29.1 was exposed to the LD 50 dose of peptide 4-1-17, small molecule 8673 or cytarabine $(45 \mathrm{nM})$ for $48 \mathrm{~h}$. (B) The ALL cell line 697 was exposed to the LD ${ }_{50}$ dose of peptide $4-1-17$, small molecule 8673 or doxorubicin $(0.1 \mu \mathrm{g} / \mathrm{ml})$ for $48 \mathrm{~h}$. (C) The AML cell line FLG 29.1 was exposed to the LD $_{50}$ dose of peptide $4-1-17$ and small molecule 8673 alone or in combination with cytarabine $(45 \mathrm{nM})$ for $48 \mathrm{~h}$. (D) The ALL cell line 697 was exposed to the LD S0 $_{50}$ of peptide $4-1-17$ and small molecule 8673 alone or in combination with doxorubicin $(0.1 \mu \mathrm{g} / \mathrm{ml})$ for $48 \mathrm{~h}$. (E) A total of two representative B cell precursor-ALL primary samples were cultured with or without MSCs and treated with $\mathrm{LD}_{50}$ doses of 8673 in the presence of doxorubicin. Values in all panels are the mean \pm standard deviation of three independent experiments. Statistical analysis was performed with one-way analysis of variance followed by Bonferroni's post hoc test. ${ }^{*} \mathrm{P}<0.05$; ${ }^{* *} \mathrm{P}<0.01$. AML, acute myeloid leukemia; ALL, acute lymphoblastic leukemia; MSC, mesenchymal stem cell; LD $_{50}$, median lethal dose. 

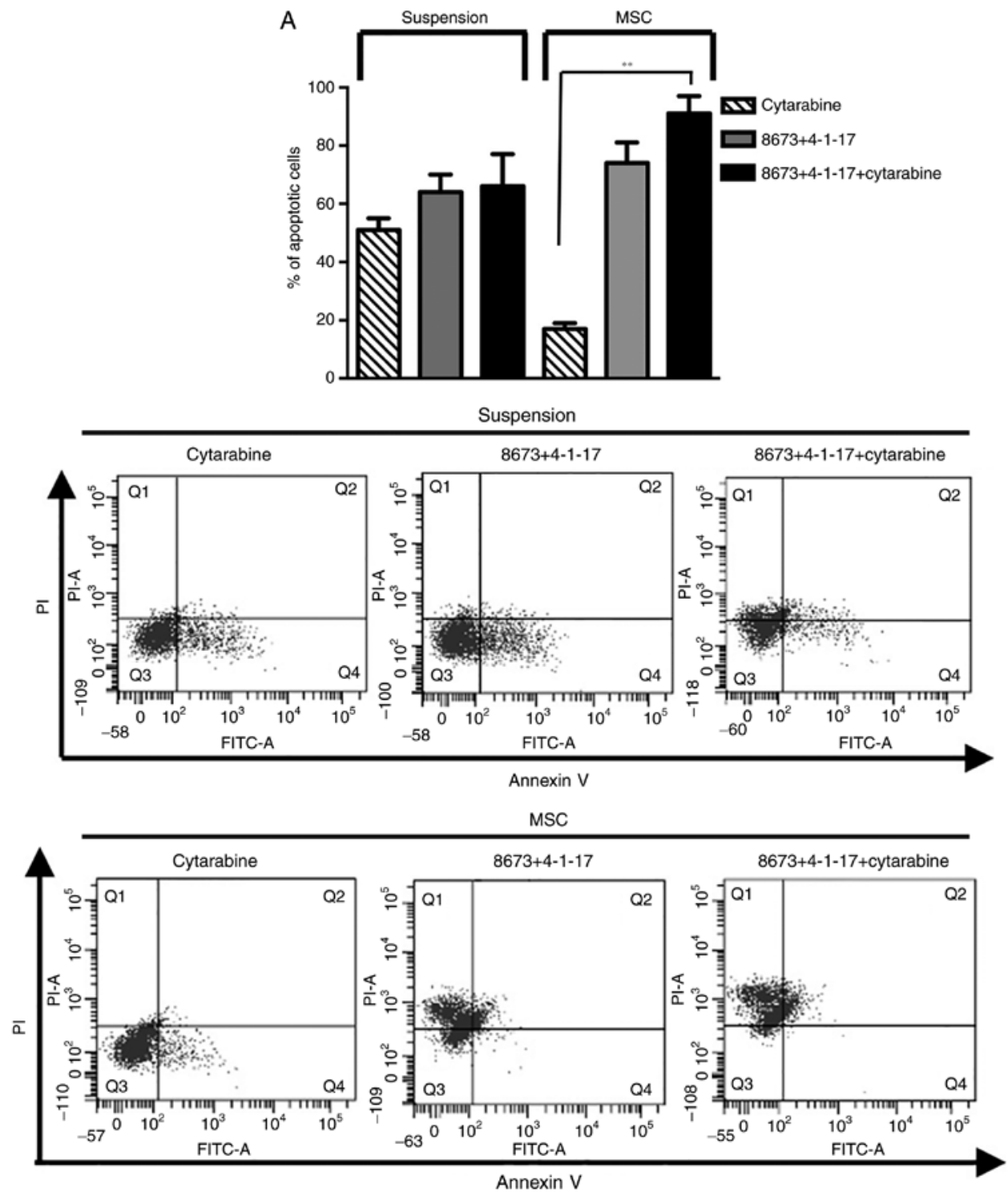

Figure 5. Combined treatment with 4-1-17 and 8673 overcomes MSC protection and activates caspase-mediated apoptosis. (A) Acute leukemia cell line (FLG 29.1, AML) was cultured with or without MSCs (suspension), and exposed to combined treatment with peptide 4-1-17 and small molecule 8673 (the LD $_{50}$ dose) alone or in the presence of cytarabine $(45 \mathrm{nM})$ for $48 \mathrm{~h}$, under normoxic conditions. The percentage of Annexin $\mathrm{V}^{+}$cells was measured. The right panels contain representative dot plots of Annexin V and PI staining in FLG 29.1 cells cultured in normoxia. Statistical analysis was performed with the one-way analysis of variance followed by Bonferroni's post hoc test.

CXCL12/CXCR4 interactions have been demonstrated to trigger Akt and ERK signaling (33); the present study therefore tested the effects of 4-1-17 and 8673, alone or in combination, on the MSC-induced activation of Akt and ERK in FLG 29.1 cells. Fig. 6 demonstrates that 4-1-17 and 8673 downregulated ERK phosphorylation induced by MSCs (left panels), and that the combined treatment abrogated MSC-induced ERK phosphorylation. Similarly, the phosphorylation of Akt was downregulated following treatment with either 4-1-17 or 8673, an effect particularly evident when MSCs were added to the leukemia cells (right panels).

Since hypoxia has a relevant impact on leukemic cell survival (34), the effect of the combined treatment was assessed in FLG 29.1 cells cultured either in suspension or onto MSCs in hypoxic conditions. Similar to what was observed in normoxia, the addition of 4-1-17 and 8673 induced a pro-apoptotic effect and overcame MSC-mediated chemoresistance (Fig. 7).

\section{Discussion}

The present study provided evidence that two different molecular tools targeting the CXCL12/CXCR4 complex, peptide 4-1-17 and the small molecule 8673, inhibited the proliferation of AML and ALL cell lines by inducing apoptosis. In contrast to what occurs with chemotherapeutic drugs, this effect was not reduced by the presence of MSCs. Furthermore, the two tools significantly increased the sensitivity of leukemic cells to cytarabine in the presence of MSCs.

The principal cause of treatment failure in acute leukemia, particularly in the pediatric setting, which is generally associated with better outcomes, is chemotherapy resistance $(3,35)$. Leukemic cells have been reported to take refuge within the BM niche (36), which thus leads to survival of residual leukemic cells following chemotherapy, resulting in disease relapse. In other words, leukemic cells that adhere to MSCs 

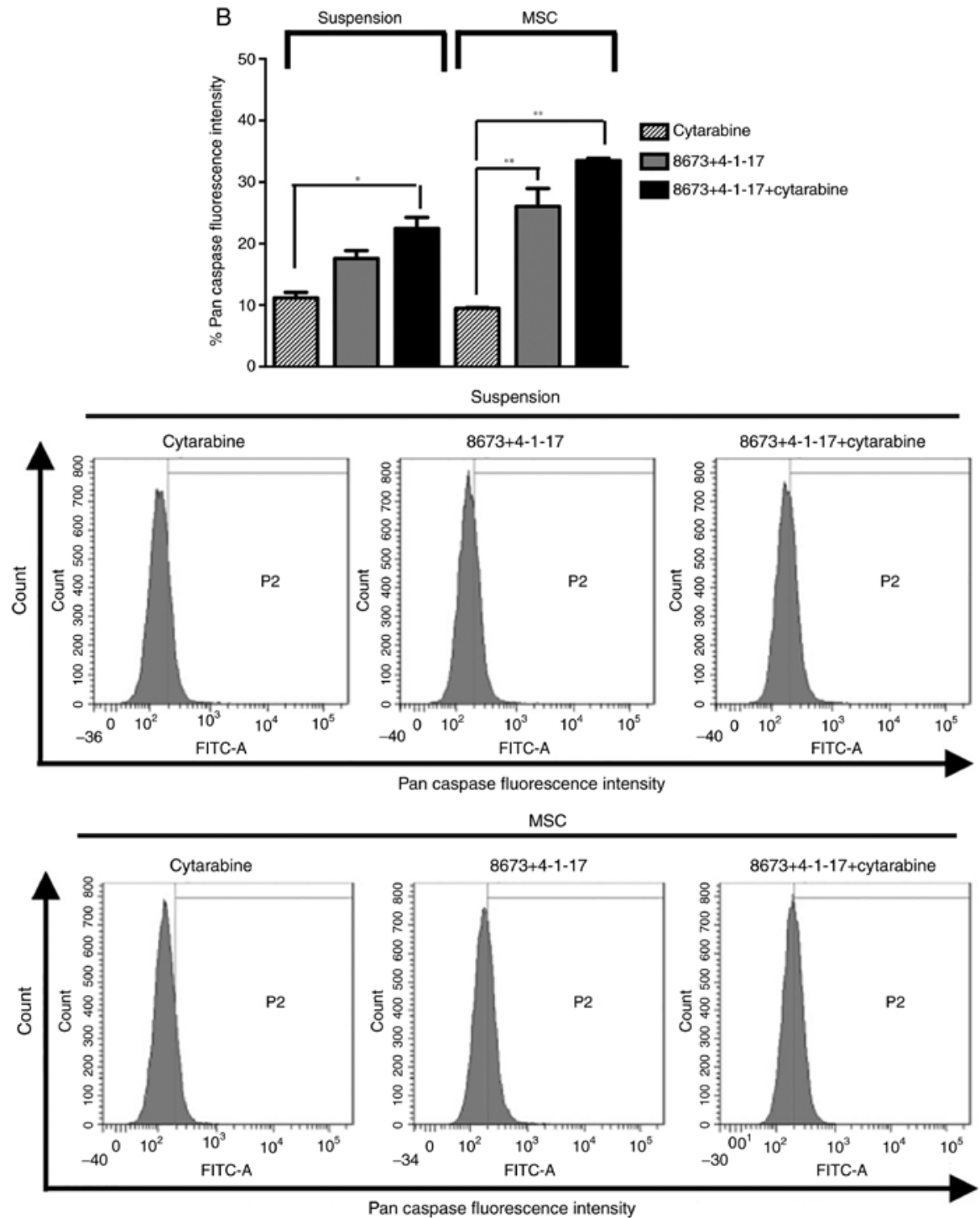

Figure 5. Continued. (B) Caspase-activity in FLG 29.1 cells, cultured with or without MSCs and exposed under normoxic conditions for $48 \mathrm{~h}$. Representative histograms for pan-caspase analysis are presented on the right. The right side of the vertical line indicates the pan-caspase-positive region in each panel. The position of this line was the same for all treatments, as the control setting. Values in all panels are the mean \pm standard deviation of three independent experiments. Statistical analysis was performed with one-way analysis of variance followed by Bonferroni's post hoc test. ${ }^{*} \mathrm{P}<0.05$; ${ }^{* *} \mathrm{P}<0.01$. FITC, fluorescein isothiocyanate; PI, propidium iodide; MSC, mesenchymal stem cell.
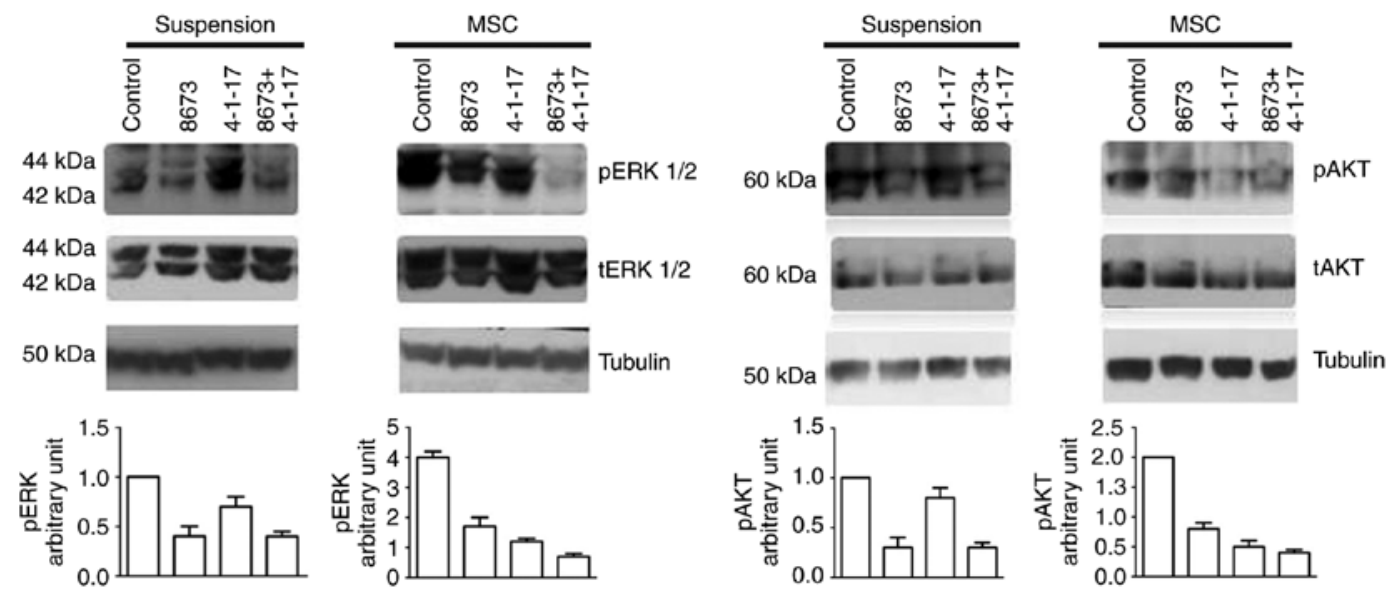

Figure 6. Combined treatment with 4-1-17 and 8673 inhibits MSC-induced activation of Akt and ERK. Acute leukemia cells (FLG 29.1) were cultured with or without MSCs (suspension) and exposed to the $\mathrm{LD}_{50}$ dose of peptide 4-1-17 and small molecule 8673, alone or in combination, for 48 h. Phosphorylation of p-ERK1/2 $2^{\mathrm{Thr} 202 / \mathrm{Tyr} 204}(42 / 44 \mathrm{kDa})$ and p-Akt ${ }^{\mathrm{Th} 308}(60 \mathrm{kDa})$ was detected by western blot analysis. Membranes were also reprobed with an anti-ERK1/2, anti-Akt or anti-tubulin antibody. The corresponding densitometric analyses are presented in the bar graphs, displayed as the ratios of p-proteins to total proteins. Akt, RAC- $\alpha$ serine/threonine-protein kinase; ERK, extracellular signal-regulated kinase; MSC, mesenchymal stem cell; p, phosphorylated. 

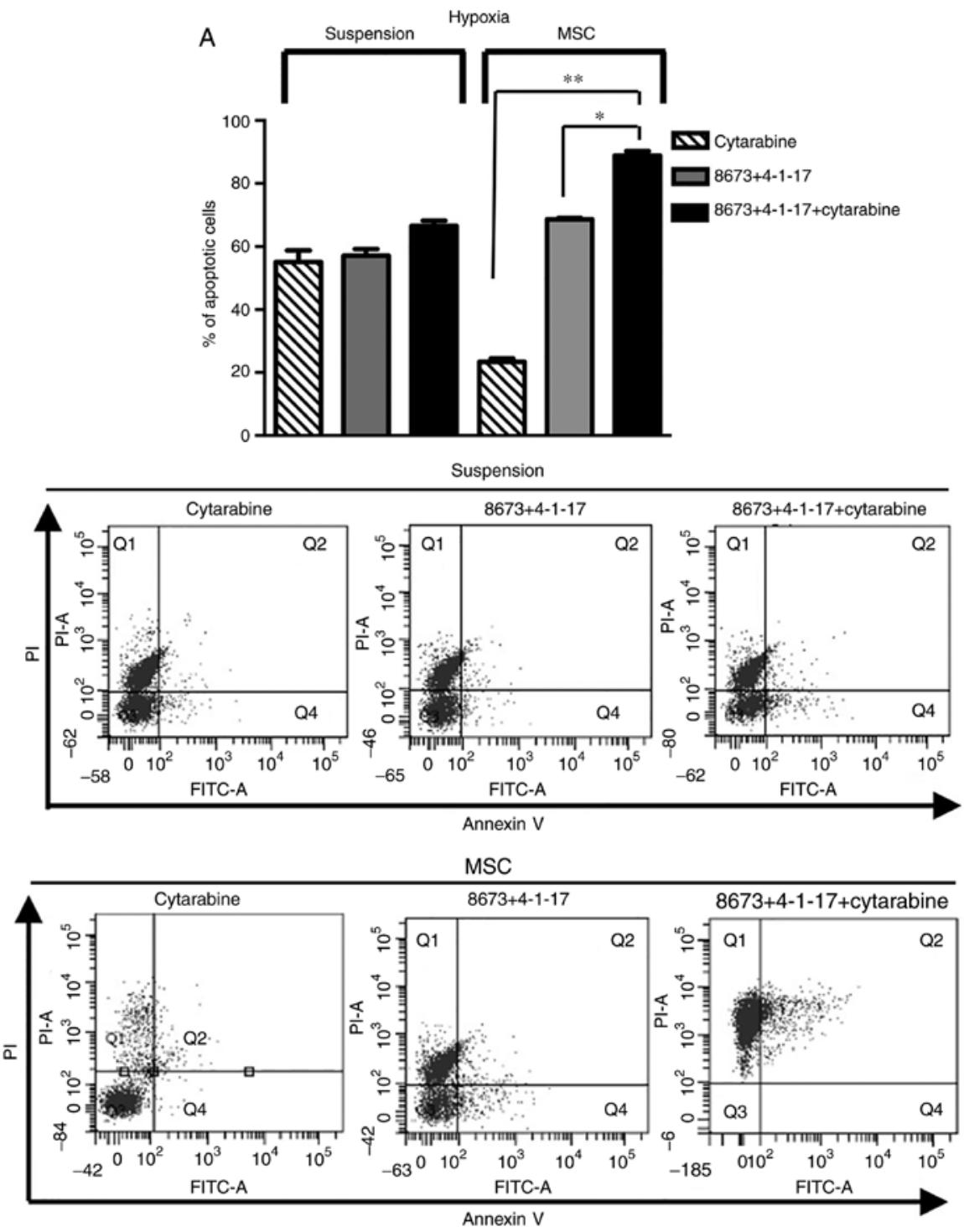

Figure 7. Addition of 4-1-17 and 8673 in hypoxic conditions induces a pro-apoptotic effect and an overcoming of MSC-associated chemoresistance. (A) The acute leukemia cell line (FLG 29.1; acute myeloid leukemia) was cultured with or without MSCs (suspension) and exposed to combined treatment with peptide 4-1-17 and small molecule 8673 (the $\mathrm{LD}_{50}$ dose) alone or in the presence of cytarabine $(45 \mathrm{nM})$ for $48 \mathrm{~h}$, under hypoxic conditions $\left(0.1 \% \mathrm{O}_{2}\right)$. The percentage of Annexin V+ cells was measured. Representative dot plots of Annexin V and PI staining in FLG 29.1 cells cultured under hypoxia are presented in the right-hand panels.

through CXCR4 are protected from the effects of cytotoxic chemotherapy and represent a reservoir for minimal residual disease and relapse (37). CXCL12 and its cognate receptor, CXCR4, are two key mediators in the cross-talk between leukemia cells and their microenvironment.

A novel mechanism of chemoresistance in ALL was previously elucidated, centered on a plasma membrane macromolecular complex consisting of the hERG1 potassium channel, the CXCR4 chemokine receptor and the $\beta 1$ integrin subunit (7). The role of hERG1 was critical, as hERG1 inhibitors abrogated the protective effect of MSCs and enhanced the cytotoxicity of drugs commonly used to treat leukemia. However, the targeting of hERG1 channels with classical hERG1-specific blockers is difficult to propose in the clinical setting, due to the potential cardiotoxicity displayed by classical hERG1 blockers $(13,14,38)$. For this reason, aside from using non-cardiotoxic hERG1 blockers $(15,38)$, an alternative therapeutic strategy was proposed to specifically target the
hERG1//1/CXCR4 complex, and in turn overcome chemoresistance in leukemia. Such a strategy consisted of inhibition of the interaction between CXCL12 and its receptor CXCR4 with either peptides or small molecules developed following a previously described procedure (22), and targeting the chemokine CXCL12.

Previous studies provided evidence that targeting CXCR4 with different agents (AMD3100, AMD3465, BKT140, RCP168 and TN140) increased the sensitivity of leukemia cells to chemotherapy $(33,39,40)$. AMD3100 was approved by the FDA in 2008 for the mobilization of hematopoietic stem cells as an injectable agent for short-term treatments (in patients with non-Hodgkin's lymphoma and multiple myeloma) and is currently in phase I clinical trials for AML and chronic myeloid leukemia. The safety and feasibility of combining AMD3100 with chemotherapy in patients with myeloma and lymphoma has already been demonstrated. On the contrary, concerns remain regarding the administration of AMD3100 to patients with acute leukemia. 

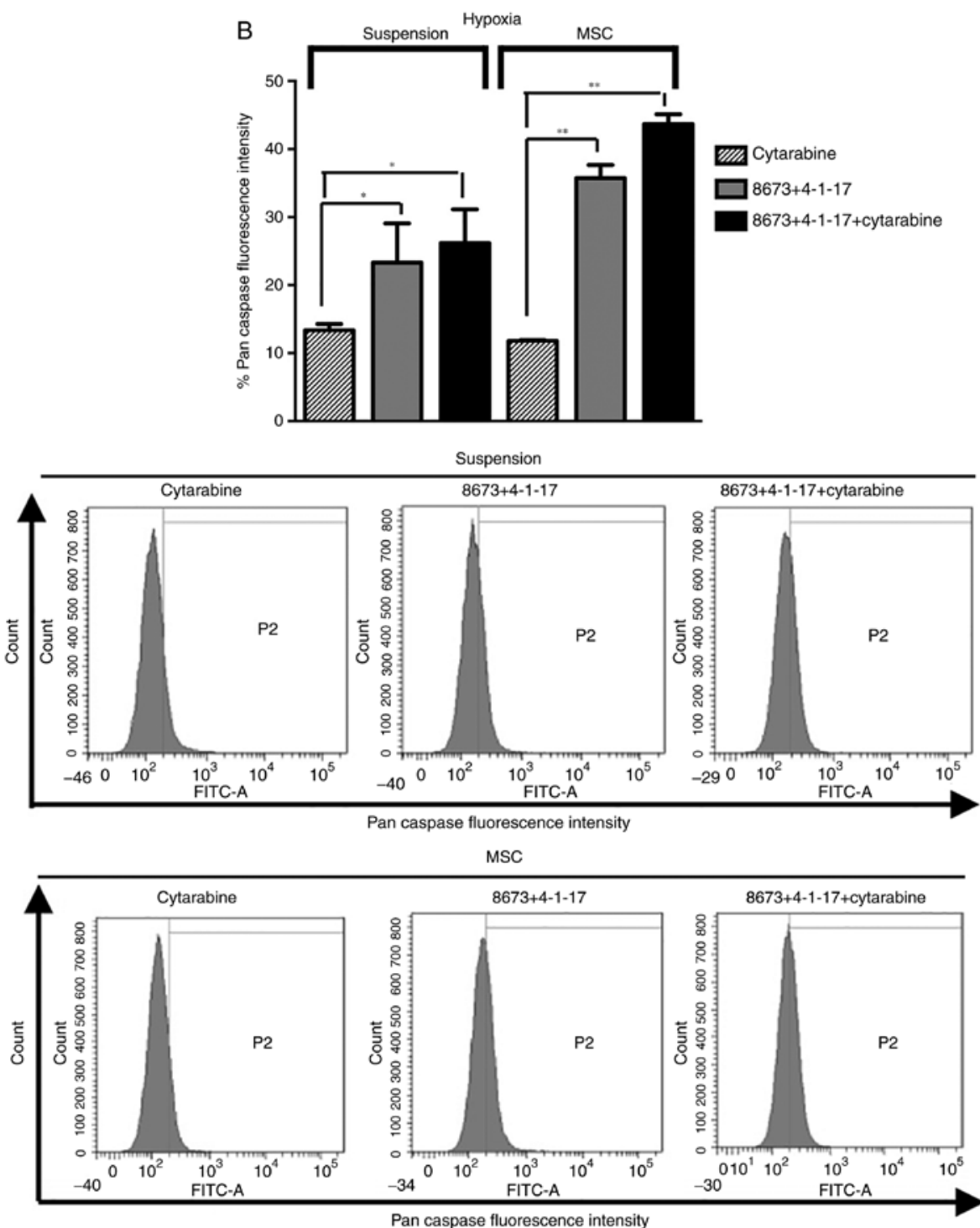

Figure 7. Continued. (B) Caspase-activity in FLG 29.1 cells, cultured with or without MSCs and exposed under hypoxic conditions $\left(0.1 \% \mathrm{O}_{2}\right)$ for $48 \mathrm{~h}$. Representative histograms for pan-caspase analysis are exhibited on the right. Representative histograms for pan-caspase analysis are presented on the right. The right side of the vertical line indicates the pan-caspase-positive region in each panel. The position of this line was the same for all treatments, as the control setting. Values in all panels are the mean \pm standard deviation of three independent experiments. Statistical analysis was performed with one-way analysis of variance followed by Bonferroni's post hoc test. $\mathrm{P}<0.05 ;{ }^{* *} \mathrm{P}<0.01$. MSC, mesenchymal stem cell; FITC, fluorescein isothiocyanate; PI, propidium iodide.

Concerns are primarily associated with BM aplasia, delayed hematopoietic recovery following chemotherapy and CXCR4 upregulation (41). In addition, such treatment may result in a preferential mobilization of leukemic blasts over normal cells. Another compound, the orally active AMD11070, which binds overlapping non-identical residues in the binding pocket of the receptor, is currently in phase I clinical trials for cancer $(42,43)$. Furthermore, a number of novel tools to block CXCR4/CXCL12 interactions are under development, being either peptides or small molecules. Among the peptide class, T140 and its stable derivative BKT140 have recently been reported to target AML anchorage in the BM, in addition to the differentiation and survival of leukemic cells (44-46). The same molecule is undergoing further development via substitution of uncharged and negatively-charged side chains with positively-charged ones. Still in the 'biological' domain, the fully human anti-CXCR4 antibody BMS-936564 has exhibited exerting effects similar to those of the AMD3100 small molecule drug, in addition to pro-apoptotic activity (47). Regarding small molecules, the isothiourea derivative IT1t has been proven to be an antagonist for CXCR4, and the structure of IT1t/CXR4 complex has been resolved by X-ray crystallography (25), opening the way to rational design of molecules with improved efficacy (48).

All of the tools reported above target the CXCR4 receptor, since chemokines are generally viewed as 'undruggable' proteins. The two molecular tools here proposed target the CXCL12/CXCR4 complex, although they bind to the ligand, CXCL12, rather than the receptor. Notably, targeting a specific ligand may facilitate regulation rather than the elimination of receptor activity. The two compounds, 4-1-17 and 8673 are very different in nature, the former being a 17-mer peptide derived from the N-terminal domain of CXCR4, and the latter, a small drug-like molecule selected by virtual screening. The two compounds target CXCL12, although they 
use distinct binding sites. Standard screening for potential drugs is usually performed by examining the static features of target protein surfaces. On the other hand, in the present study, CXCL12 structural dynamics were used as a rational framework for drug selection. Accordingly, disruptors of the CXCL12/CXCR4 interaction were predicted and tested for their activity. Thus, one peptide, which was shorter than those previously suggested, and one small molecule, which interacted with a transient hot spot, were highlighted by the present DDD approach. The fact that 4-1-17 and 8673 bind CXCL12 at different sites suggests that the conjugation of the two molecules may exhibit stronger biological activity. Taken together, the present findings demonstrated the efficacy of double targeting of CXCL12 in leukemic cells co-cultured with MSCs, either in normoxic or hypoxic conditions. In this respect, the structural features of peptide 4-1-17 and 8673 binding with CXCL12 may be used to further optimize more of the active fragments to assemble novel drugs.

Overall, the present results provided data for a novel approach to the treatment of chemoresistant acute leukemia, based on: i) The simultaneous blockade of one of the members of the CXCR4/ hERG1/ $\beta_{1}$ complex on the plasma membrane of leukemic cells, i.e. the CXCR4/CXCL12 axis; and ii) a novel approach to drug selection, based on structural dynamics analyses. Further conjugation of the two molecules targeting CXCL12 reported in the present study (4-1-17 and 8673) may be proposed to induce stronger antileukemic activity.

\section{Acknowledgements}

The authors would like to thank Professor Persio dello Sbarba (Department of Clinical and Experimental Biomedical Sciences, University of Florence, Florence, Italy) for allowing the use of the DG250 Anaerobic Workstation.

\section{Funding}

The present study was supported by grants from the Associazione Noi per Voi Onlus, Associazione Italiana per la Ricerca sul Cancro (grant nos. 15627 and 1662) to AA, Istituto Toscano Tumori 2009 to NN and ex $60 \%$ University of Firenze 2014 to SP.

\section{Availability of data and materials}

The datasets used during the present study are available from the corresponding author on reasonable request.

\section{Authors' contributions}

BL performed the peptide synthesis. AB conceived the peptide and small molecules approach, performed modelling and docking work and contributed to writing the manuscript. OS performed the bioinformatics analysis. LB and NN contributed to the analysis of the results. SP performed the cell viability assay, pharmacology experiments, western blotting and hypoxia experiments. GP performed the caspase activity assay. AA, NN and SP designed the study. AA supervised the study and wrote the paper. SP and AB revised the paper. All authors read and approved the final manuscript.

\section{Ethics approval and consent to participate}

Patients studied were enrolled in the AIEOP-BFM ALL 2009 therapy protocol, approved by the local ethical committee (Comitato Etico per la Sperimentazione dell'Azienda Ospedaliera di Padova; no. 0002862-18/01/2012). The parents or legal guardians of the patients provided written informed consent, following the tenets of the Declaration of Helsinki.

\section{Patient consent for publication}

The parents or legal guardians of the patients provided written informed consent, following the tenets of the Declaration of Helsinki.

\section{Competing interests}

The authors declare that they have no competing interests.

\section{References}

1. Pui CH, Schrappe M, Ribeiro RC and Niemeyer CM: Childhood and adolescent lymphoid and myeloid leukemia. Hematology Am Soc Hematol Educ Program: 118-145, 2004.

2. August KJ, Narendran A and Neville KA: Pediatric relapsed or refractory leukemia: New pharmacotherapeutic developments and future directions. Drugs 73: 439-461, 2013.

3. Konopleva MY and Jordan CT: Leukemia stem cells and microenvironment: Biology and therapeutic targeting. J Clin Oncol 29: 591-599, 2011.

4. Konopleva M, Tabe Y, Zeng Z and Andreeff M: Therapeutic targeting of microenvironmental interactions in leukemia: Mechanisms and approaches. Drug Resist Updat 12: 103-113, 2009.

5. Tavor S and Petit I: Can inhibition of the SDF-1/CXCR4 axis eradicate acute leukemia? Semin Cancer Biol 20: 178-185, 2010.

6. Peled A and Tavor S: Role of CXCR4 in the pathogenesis of acute myeloid leukemia. Theranostics 3: 34-39, 2013.

7. Pillozzi S, Masselli M, De Lorenzo E, Accordi B, Cilia E, Crociani O, Amedei A, Veltroni M, D'Amico M, Basso G, et al: Chemotherapy resistance in acute lymphoblastic leukemia requires hERG1 channels and is overcome by hERG1 blockers. Blood 117: 902-914, 2011.

8. Li H, Du YM, Guo L, Jie S, Zhang S, Du W, Chen X, Liu W, Fan L, Zhu J, et al: The role of hERG1 $\mathrm{K}^{+}$channels and a functional link between hERG1 $\mathrm{K}_{+}$channels and SDF-1 in acute leukemic cell migration. Exp Cell Res 315: 2256-2264, 2008.

9. Pillozzi S, Brizzi MF, Balzi M, Crociani O, Cherubini A, Guasti L, Bartolozzi B, Becchetti A, Wanke E, Bernabei PA, et al: HERG potassium channels are constitutively expressed in primary human acute myeloid leukemias and regulate cell proliferation of normal and leukemic hemopoietic progenitors. Leukemia 16: 1791-1798, 2002

10. Pillozzi S, Brizzi MF, Bernabei PA, Bartolozzi B, Caporale R, Basile V, Pegoraro L, Becchetti A and Arcangeli A: VEGFR-1 (FLT-1), $\beta_{1}$ integrin, and $\mathrm{hERG} \mathrm{K}{ }^{+}$channel for a macromolecular signaling complex in acute myeloid leukemia: Role in cell migration and clinical outcome. Blood 110: 1238-1250, 2007.

11. Erdem M, Tekiner TA, Fejzullahu A, Akan G, Anak S, Saribeyoglu ET, Ozbek U and Atalar F: herglb expression as a potential specific marker in pediatric acute myeloid leukemia patients with HERG $897 \mathrm{~K} / \mathrm{K}$ genotype. Pediatr Hematol Oncol 32: 182-192, 2015.

12. Pillozzi S, Accordi B, Rebora P, Serafin V, Valsecchi MG, Basso G and Arcangeli A: Differential expression of $h E R G 1 A$ and $h E R G 1 B$ genes in pediatric acute lymphoblastic leukemia identifies different prognostic subgroups. Leukemia 28: 1352-1355, 2014.

13. Redfern WS, Carlsson L, Davis AS, Lynch WG, MacKenzie I Palethorpe S, Siegl PK, Strang I, Sullivan AT, Wallis R, et al: Relationships between preclinical cardiac electrophysiology, clinical QT interval prolongation and torsade de pointes for a broad range of drugs: evidence for a provisional safety margin in drug development. Cardiovasc Res 58: 32-45, 2003. 
14. Vandenberg JI, Perry MD, Perrin MJ, Mann SA, Ke Y and Hill AP: hERG $\mathrm{K}^{+}$channels: Structure, function, and clinical significance. Physiol Rev 92: 1393-1478, 2012.

15. Gasparoli L, D'Amico M, Masselli M, Pillozzi S, Caves R, Khuwaileh R, Tiedke W, Mugridge K, Pratesi A, Mitcheson JS et al: New pyrimido-indole compound CD-160130 preferentially inhibits the KV11.1B isoform and produces antileukemic effects without cardiotoxicity. Mol Pharmacol 87: 183-196, 2015

16. Spoo AC, Lübbert M, Wierda WG and Burger JA: CXCR4 is a prognostic marker in acute myelogenous leukemia. Blood 109: 786-791, 2007

17. Fecteau JF, Messmer D, Zhang S, Cui B, Chen L and Kipps TJ: Impact of oxygen concentration on growth of mesenchymal stromal cells from the marrow of patients with chronic lymphocytic leukemia. Blood 121: 971-974, 2013.

18. Sison EA, McIntyre E, Magoon D and Brown P: Dynamic chemotherapy-induced upregulation of CXCR4 expression: A mechanism of therapeutic resistance in pediatric AML. Mol Cancer Res 11: 1004-1016, 2013.

19. Baba M, Takashima K, Miyake H, Kanzaki N, Teshima K, Wang X, Shiraishi M and Iizawa Y: TAK-652 inhibits CCR5-mediated human immunodeficiency virus type 1 infection in vitro and has favorable pharmacokinetics in humans. Antimicrob Agents Chemother 49: 4584-4591, 2005.

20. Nichols WG, Steel HM, Bonny T, Adkison K, Curtis L, Millard J, Kabeya K and Clumeck N: Hepatotoxicity observed in clinical trials of aplaviroc (GW873140). Antimicrob Agents Chemother 52: 858-865, 2008.

21. Hachet-Haas M, Balabanian K, Rohmer F, Pons F, Franchet C, Lecat S, Chow KY, Dagher R, Gizzi P, Didier B, et al: Small neutralizing molecules to inhibit actions of the chemokine CXCL12. J Biol Chem 283: 23189-23199, 2008.

22. Bernini A, Henrici De Angelis L, Morandi E, Spiga O, Santucci A, Assfalg M, Molinari H, Pillozzi S, Arcangeli A and Niccolai N: Searching for protein binding sites from Molecular Dynamics simulations and paramagnetic fragment-based NMR studies. Biochim Biophys Acta 1844: 561-566, 2013.

23. Trott $\mathrm{O}$ and Olson AJ: AutoDock Vina: Improving the speed and accuracy of docking with a new scoring function, efficient optimization, and multithreading. J Comput Chem 31: 455-461, 2010.

24. Zhou N, Luo Z, Luo J, Liu D, Hall JW, Pomerantz RJ and Huang Z: Structural and functional characterization of human CXCR4 as a chemokine receptor and HIV-1 co-receptor by mutagenesis and molecular modeling studies. J Biol Chem 276: 42826-42833, 2001

25. Wu B, Chien EY, Mol CD, Fenalti G, Liu W, Katritch V, Abagyan R, Brooun A, Wells P, Bi FC, et al: Structures of the CXCR4 chemokine GPCR with small-molecule and cyclic peptide antagonists. Science 330: 1066-1071, 2010

26. Gozansky EK, Louis JM, Caffrey M and Clore GM: Mapping the binding of the N-terminal extracellular tail of the CXCR4 receptor to stromal cell-derived factor-1alpha. J Mol Biol 345: 651-658, 2005

27. Veldkamp CT, Seibert C, Peterson FC, De la Cruz NB Haugner JC III, Basnet H, Sakmar TP and Volkman BF: Structural basis of CXCR4 sulfotyrosine recognition by the chemokine SDF-1/CXCL12. Sci Signal 1: ra4, 2008.

28. Sun X, Cheng G, Hao M, Zheng J, Zhou X, Zhang J, Taichman RS Pienta KJ and Wang J: CXCL12/CXCR4/CXCR7 chemokine axis and cancer progression. Cancer Metastasis Rev 29: 709-722, 2010.

29. Costantini S, Raucci R, De Vero T, Castello G and Colonna G: Common structural interactions between the receptors CXCR3, CXCR4 and CXCR7 complexed with their natural ligands, CXCL11 and CXCL12, by a modeling approach. Cytokine 64: 316-321, 2013.

30. Irwin JJ, Sterling T, Mysinger M, Bolstad ES and Coleman RG: ZINC: A free tool to discover chemistry for biology. J Chem Inf Model 52: 1757-1768, 2012

31. Veldkamp CT, Ziarek JJ, Peterson FC, Chen Y and Volkman BF: Targeting SDF-1/CXCL12 with a ligand that prevents activation of CXCR4 through structure-based drug design. J Am Chem Soc 132: 7242-7243, 2010.

32. Konopleva M, Konoplev S, Hu W, Zaritskey AY, Afanasiev BV and Andreeff M: Stromal cells prevent apoptosis of AML cells by up-regulation of anti-apoptotic proteins. Leukemia 16: $1713-1724,2002$
33. Zeng Z, Samudio IJ, Munsell M, An J, Huang Z, Estey E, Andreeff $M$ and Konopleva M: Inhibition of CXCR4 with the novel RCP168 peptide overcomes stroma-mediated chemoresistance in chronic and acute leukemias. Mol Cancer Ther 5: 3113-3121, 2006

34. Rashidi A and DiPersio JF: Targeting the leukemia-stroma interaction in acute myeloid leukemia: Rationale and latest evidence. Ther Adv Hematol 7: 40-51, 2016.

35. Estey E and Döhner H: Acute myeloid leukemia. Lancet 368 1894-1907, 2006.

36. Colmone A, Amorim M, Pontier AL, Wang S, Jablonski E and Sipkins DA: Leukemic cells create bone marrow niches that disrupt the behavior of normal hematopoietic progenitor cells. Science 322: 1861-1865, 2008.

37. Lagneaux L, Delforge A, Bron D, De Bruyn C and Stryckmans P: Chronic lymphocytic leukemia B cells but not normal B cells are rescued from apoptosis by contact with normal bone marrow stromal cells. Blood 91: 2387-2396, 1998

38. Pillozzi S, Masselli M, Gasparoli L, D'Amico M, Polletta L, Veltroni M, Favre C, Basso G, Becchetti A and Arcangeli A: Macrolide antibiotics exert antileukemic effects by modulating the autophagic flux through inhibition of hERG1 potassium channels. Blood Cancer J 6: e423, 2016.

39. Beider K, Begin M, Abraham M, Wald H, Weiss ID, Wald O, Pikarsky E, Zeira E, Eizenberg O, Galun E, et al: CXCR4 antagonist 4F-benzoyl-TN14003 inhibits leukemia and multiple myeloma tumor growth. Exp Hematol 39: 282-292, 2011.

40. Zhang Y, Patel S, Abdelouahab H, Wittner M, Willekens C, Shen S, Betems A, Joulin V, Opolon P, Bawa O, et al: CXCR4 inhibitors selectively eliminate CXCR4-expressing human acute myeloid leukemia cells in NOG mouse model. Cell Death Dis 3: e396, 2012.

41. Uy GL, Rettig MP, Stone RM, Konopleva MY, Andreeff M, McFarland K, Shannon W, Fletcher TR, Reineck T, Eades W, et al: A phase $1 / 2$ study of chemosensitization with plerixafor plus G-CSF in relapsed or refractory acute myeloid leukemia. Blood Cancer J 7: e542, 2017.

42. Parameswaran R, Yu M, Lim M, Groffen J and Heisterkamp N Combination of drug therapy in acute lymphoblastic leukemia with a CXCR4 antagonist. Leukemia 25: 1314-1323, 2011.

43. O'Boyle G, Swidenbank I, Marshall H, Barker CE, Armstrong J, White SA, Fricker SP, Plummer R, Wright $M$ and Lovat PE: Inhibition of CXCR4-CXCL12 chemotaxis in melanoma by AMD11070. Br J Cancer 108: 1634-1640, 2013.

44. Feng Z, Dubyak GR, Jia X, Lubkowski JT and Weinberg A: Human $\beta$-defensin-3 structure motifs that are important in CXCR4 antagonism. FEBS J 280: 3365-3375, 2013.

45. Beider K, Darash-Yahana M, Blaier O, Koren-Michowitz M, Abraham M, Wald H, Wald O, Galun E, Eizenberg O, Peled A, et al: Combination of imatinib with CXCR4 antagonist BKT140 overcomes the protective effect of stroma and targets CML in vitro and in vivo. Mol Cancer Ther 13: 1155-1169, 2014.

46. Abraham M, Klein S, Bulvik B, Wald H, Weiss ID, Olam D, Weiss L, Beider K, Eizenberg O, Wald O, et al: The CXCR4 inhibitor BL-8040 induces the apoptosis of AML blasts by downregulating ERK, BCL-2, MCL-1 and cyclin-D1 via altered miR-15a/16-1 expression. Leukemia 31: 2336-2346, 2017.

47. Kashyap MK, Kumar D, Jones H, Amaya-Chanaga CI, Choi MY, Melo-Cardenas J, Ale-Ali A, Kuhne MR, Sabbatini P, Cohen LJ, et al: Ulocuplumab (BMS-936564 / MDX1338): A fully human anti-CXCR4 antibody induces cell death in chronic lymphocytic leukemia mediated through a reactive oxygen species-dependent pathway. Oncotarget 7: 2809-2822, 2016.

48. Das D, Maeda K, Hayashi Y, Gavande N, Desai DV, Chang SB, Ghosh AK and Mitsuya H: Insights into the mechanism of inhibition of CXCR4: identification of Piperidinylethanamine analogs as anti-HIV-1 inhibitors. Antimicrob Agents Chemother 59: $1895-1904,2015$ 